\title{
Investigation of Proliferative Activity in the Developing Human Tooth Using Ki-67 Immunostaining
}

\author{
Gunseli Guven $^{\mathrm{a}}$ Omer Gunhan ${ }^{\mathrm{b}} \quad$ Erman Akbulut ${ }^{\mathrm{a}} \quad$ Zafer C. Cehrelic $^{\mathrm{c}}$ \\ ${ }^{a}$ Department of Pediatric Dentistry, Center of Dental Sciences, ${ }^{b}$ Department of Pathology, Gulhane Medical \\ Academy, and ' Department of Pediatric Dentistry, Faculty of Dentistry, Hacettepe University, Ankara, Turkey
}

\section{Key Words}

Ki-67 · Immunostaining $\cdot$ Proliferation $\cdot$ Tooth development

\begin{abstract}
Objective: The aim of this study was to investigate the proliferation of the developing human tooth germ and its surrounding tissues using Ki-67 immunostaining. Materials and Methods: Sections of mandibular dental arch tissues collected from 4 cadaveric human fetuses of 13, 16, 21 and 30 weeks of gestation were used. The immunoreactivity of $\mathrm{Ki}-67$ in the tissue sections was assessed visually under a light microscope. Immunohistochemical controls were performed by replacing the primary antibody with phosphatebuffered saline or normal rabbit lgG. Results: The control sections did not display Ki-67 immunoactivity. Specimens of 13 weeks of gestation revealed intense Ki-67 immunostaining throughout the entire developing mandibular primary molars. At 16 weeks of gestation, immunostaining was observed in the inner enamel epithelium and dental papilla, in conjunction with the dental lamina showing decreased immunostaining. At 21 weeks, Ki-67 immunostaining was observed only in the inner enamel epithelium and dental papilla. The immunoreactivity of active ameloblasts and odontoblasts decreased, along with the proliferation capacity of the dental lamina. At 30 weeks, both enamel and dentin formation was observed along the cusped aspect of the tooth germ. Ameloblasts and odontoblasts were no longer
\end{abstract}

immunoreactive in this region, while both types of cells were immunoreactive at the cervical regions of the crown. Dental lamina cells showed disintegration and were totally Ki-67negative at 30 weeks of gestation. Conclusion: The Ki- 67 immunoreactivity of the dental lamina decreased during intrauterine tooth development. Positive immunostaining was observed at specific sites in the enamel organ and dental papilla during the cap and bell stages.

Copyright $\odot 2007$ S. Karger AG, Basel

\section{Introduction}

Tooth development is a highly coordinated and complex process that relies on cell-to-cell interactions [1]. Basically, the crowns of the teeth consist of 2 hard matrix components: dentin, a core of calcified material, and enamel, an apical cap of a much harder material. Within the dentin resides a central pulp of connective tissue and blood vessels [2]. The enamel organ is derived from ectodermal cells lining the primitive stomadeum. The internal epithelium of the enamel is induced by ectomesenchymal cells of the dentine papilla to develop into ameloblasts which are ultimately responsible for the production of enamel, while ectomesenchymal cells of the dental papilla and follicle produce the dentin, pulp and periodontal apparatus [3].

\section{KARGER}

Fax +4161306 1234 E-Mail karger@karger.ch www.karger.com (c) 2007 S. Karger AG, Basel

$1011-7571 / 07 / 0166-0454 \$ 23.50 / 0$

Accessible online at:

www.karger.com/mpp
Dr. Gunseli Guven

Gulhane Askeri Tip Akademisi

Dishekimliği Bilimleri Merkezi, Pedodonti Anabilim Dali, Etlik

TR-06018 Ankara (Turkey)

Tel. +90 31230460 39, Fax +90 31230460 20, E-Mail guvengunseli@yahoo.com 
The first morphological evidence of odontogenesis is the formation of a primary thickening of the oral epithelium. In the human embryo, this process begins during the 6th week of prenatal development [4]. At the bud stage, the epithelium of the dental lamina grows into the underlying neural-crest-derived mesenchyme and forms an epithelial bud, around which the mesenchymal cells condense $[2,5]$. As a result of epithelial folding, the so-called cap stage is reached at weeks 13-16 of gestation. Along the concave border of the cap, the epithelium differentiates into a regular layer of columnar enamel-producing cells known as ameloblasts. The dental papilla is the condensed neural crest mesenchyme surrounded by the enamel organ. When tooth development reaches the bell stage (16-21 weeks of gestation), a layer of mesenchymal cells form on the surface of the dental papilla, facing the layer of preameloblasts. These cells, which ultimately secrete dentin, are called odontoblasts. By the late bell stage, the ameloblasts and odontoblasts begin to secrete precursors of first dentine and then enamel, starting first at the incisal region of the tooth $[2,5,6]$.

The dental lamina, which is responsible for the formation of the tooth bud, undergoes apoptosis and disintegrates during the cap and bell stages, and almost totally vanishes at the end of tooth development [5]. However, remnants of the dental lamina may remain deep in the oral mucosa or alveolar bone. These remnants are among the most important sources of the development of odontogenic cysts and odontogenic tumors $[7,8]$. Although apoptosis of the dental lamina epithelium is a well-known fact [5], the sequence and the cellular and molecular events of the disruption of the dental lamina is still a matter of extensive research.

$\mathrm{Ki}-67$, a non-histone protein, is a proliferation marker expressed by proliferating cells [7, 9-12]. The most sensitive antibody for immunohistochemical detection of the $\mathrm{Ki}-67$ antigen in paraffin sections is clone MIB-1. This antibody is widely used in various tissues for the detection of proliferation [13].

Tooth development is achieved by several dynamic processes, including cell proliferation, differentiation and cell death [14-18]. Detailed knowledge of these processes is necessary for the understanding of general outlines of tooth development and correct interpretation of molecular biological data [9], especially in the human. Consequently, the aim of this study was to investigate changes in the proliferative activities of the ameloblast and odontoblast lineage cells during tooth development, using human cadaveric specimens.

Ki-67 Immunostaining in the Developing Tooth

\section{Materials and Methods}

This study was performed following the approval of the Institutional Human Studies Ethics Committee (Approval Document No: 1491-144-2005). Human fetal tissues were obtained with legal approval from spontaneous abortions. The material comprised mandibular dental arch tissues $(0.5-1 \mathrm{~cm}$ from the mandibular corpus) and mandibular primary first molar germs collected from 4 available cadaveric human embryos of 13,16, 21 and 30 weeks of gestation. The gestation age was estimated from the fetal foot length and the last menstruation of the mothers. The embryos were macroscopically normal.

Tissue samples (of $4 \mathrm{~mm}$ greatest diameter) were fixed in $10 \%$ neutral phosphate-buffered formaldehyde and processed. Paraffin-embedded tissue blocks were cut in 6 - $\mu \mathrm{m}$-thick serial sections and placed on poly-L-lysine-treated slides. Slides were stained with hematoxylin and eosin.

In order to detect Ki-67 antigen, a commercial immunohistochemical kit (Ki-67, Clone MIB-1, mouse monoclonal antibody, Neomarkers, Union City, Calif., USA) was used. An avidin-biotin-peroxidase complex kit was used for the detection of immunoreaction against the primary antibodies. The slides were counterstained with methylene blue.

The immunoreactivity of Ki-67 in the tissue sections was assessed visually under a light microscope (Axiposcop 2 Plus, Carl Zeiss, Jena, Germany) and photographed with a digital camera (AVT Horn CCD, Sony Corp., Tokyo, Japan). Immunohistochemical controls were performed by replacing the primary antibody with phosphate-buffered saline or normal rabbit IgG.

\section{Results}

The control sections did not display Ki-67 immunoreactivity. The chronological changes in the proliferative activity of cell types are summarized in table 1 . Ki-67 immunostaining was detected in the cells at the following locations of the developing mandibular teeth and surrounding tissues:

\section{Week 13 of Gestation}

The epithelial bud had begun to acquire a cap shape known as the early cap stage. Positive immunostaining of Ki-67 was observed in the entire developing tooth. The dental lamina showed slight immunostaining compared to the other regions of the tooth germ. Intense Ki-67 immunostaining was observed mainly in the dental ectomesenchyme and the dental epithelium of the primary mandibular first molar (fig. 1).

\section{Week 16 of Gestation}

The dental epithelium developed into the cap configuration called the cap stage and constituted the enamel organ, consisting of 3 separate layers: the outer enamel epi-

Med Princ Pract 2007:16:454-459 


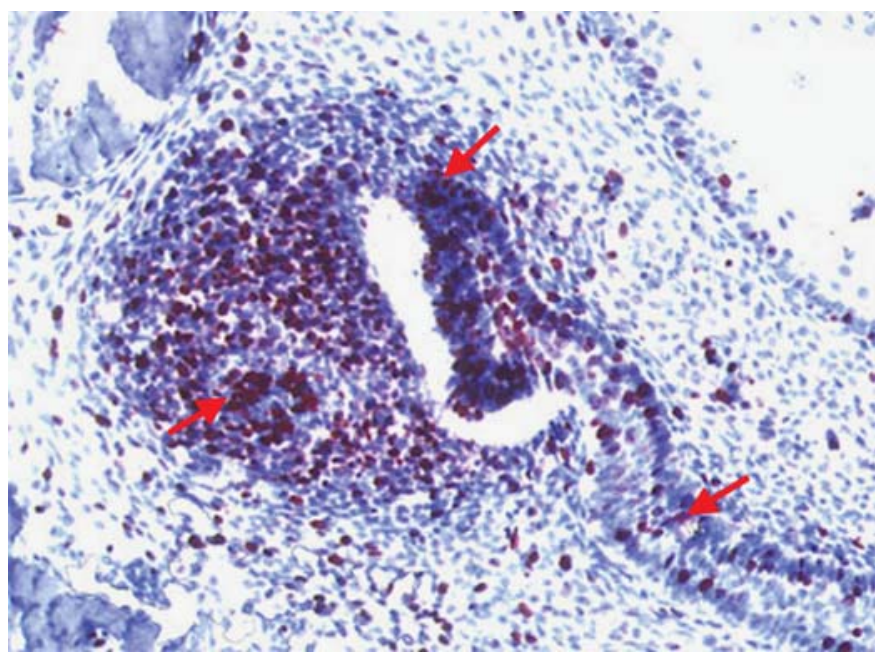

Fig. 1. Ki-67-positive cells in the whole tooth primordia of the mandibular primary first molar (arrows). Original magnification $100 \times$.

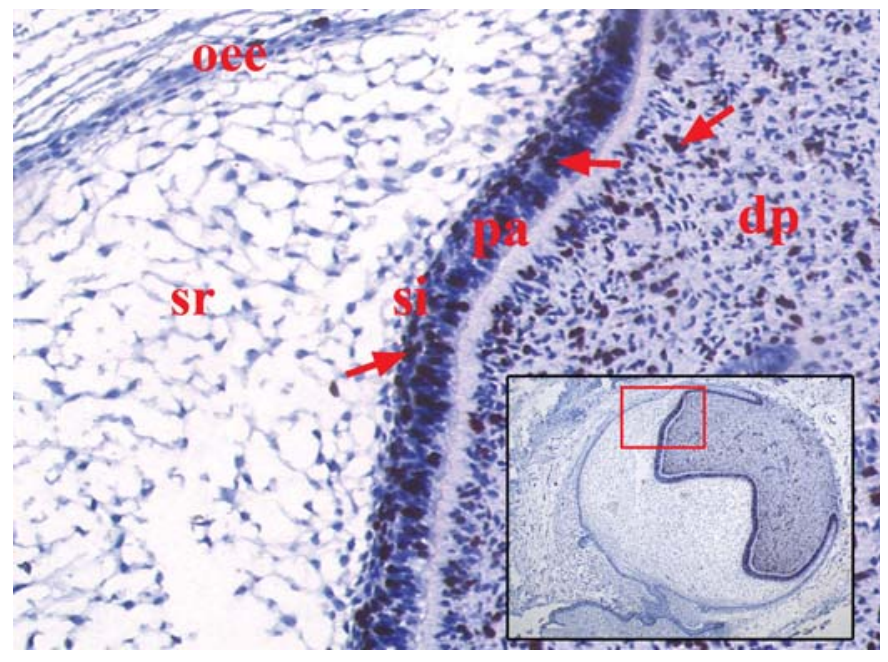

Fig. 2. Ki-67 immunoreactivity (arrows) of the stratum intermedium (si), preameloblasts (pa), and dental papilla (dp) in the mandibular primary first molar. There is no immunostaining in the outer enamel epithelium (oee) and a small number of stained cells in the stellate reticulum (sr). Original magnification $100 \times$. Inset Low magnification $(25 \times)$ of the mandibular primary first molar, indicating the region of higher magnification.

Table 1. Summary of chronological changes in the proliferative activity of cell types

\begin{tabular}{lllllllllll}
\hline $\begin{array}{l}\text { Age, weeks } \\
\text { of gestation }\end{array}$ & $\mathrm{dl}$ & $\mathrm{de}$ & $\mathrm{dm}$ & oee & iee & sr & si & pab & ab & ob \\
\hline 13 & ++ & ++ & ++ & ++ & ++ & & & & \\
16 & + & & ++ & ++ & ++ & + & ++ & + & & - \\
21 & $+/-$ & & ++ & - & + & - & ++ & & - & - \\
30 & - & & + & - & + & - & + & & - & - \\
\hline
\end{tabular}

$\mathrm{dl}=$ Dental lamina; $\mathrm{de}=$ dental epithelium; $\mathrm{dm}=$ dental mesenchyme/dental papilla; oee $=$ outer enamel epithelium; iee = inner enamel epithelium; sr = stellate reticulum; si = stratum intermedium; pab = preameloblasts; $\mathrm{ab}=$ ameloblasts; $\mathrm{ob}=$ odontoblasts $++=$ intense immunostaining, $+=$ slight immunostaining, $-=$ no immunostaining.

thelium, the stellate reticulum, and the inner enamel epithelium. During this stage, the outer enamel epithelium stained Ki-67 negative while the stellate reticulum displayed a few Ki- 67 positive cells in the center (fig. 2). However, intense Ki-67 immunostaining of the inner enamel epithelium was evident. The inner enamel epithelium started to differentiate; forming columnar cells (preameloblasts) facing the dental papilla. Deep in the preameloblasts, an intense cell layer (stratum intermedium, the precursor of the preameloblasts) was observed. The stratum intermedium showed more immunostaining the pre- ameloblasts (fig. 2). The dental mesenchyme progressively formed dental papilla at this stage, and fibroblasts of the dental papilla were strongly Ki-67 positive (fig. 2). Intense Ki-67 immunostaining was also observed in the mesenchyme that invaginated deep into the tooth bell. Degeneration of the dental lamina started at this stage and showed weak Ki-67 immunostaining (fig. 3).

\section{Week 21 of Gestation}

At this stage, the tooth germ was in the early bell stage of development, in which a layer of odontoblasts had 


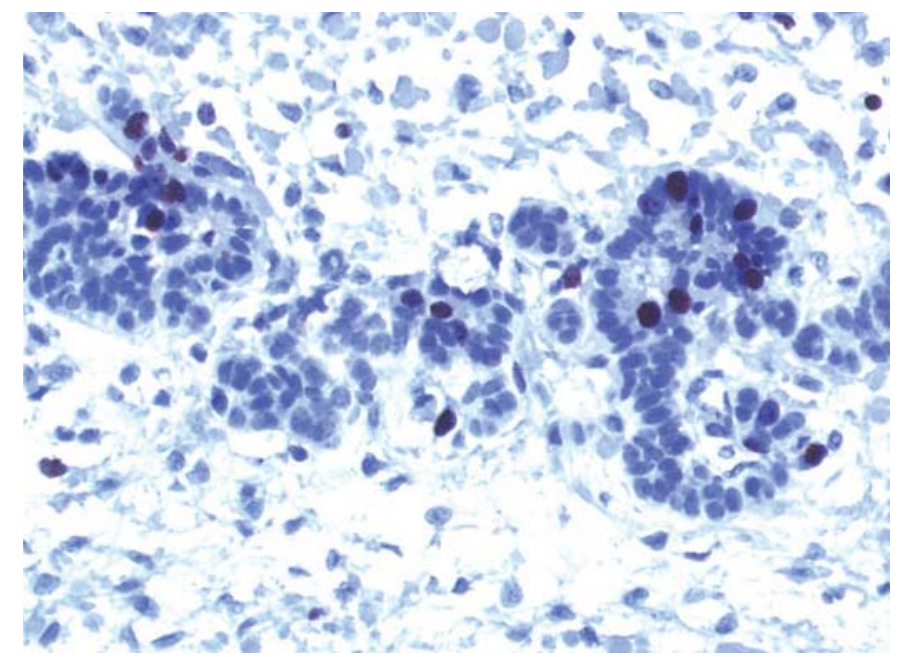

Fig. 3. Degeneration of the dental lamina with weak Ki-67 immunostaining at the late cap stage. Mandibular primary first molar. Original magnification $200 \times$.

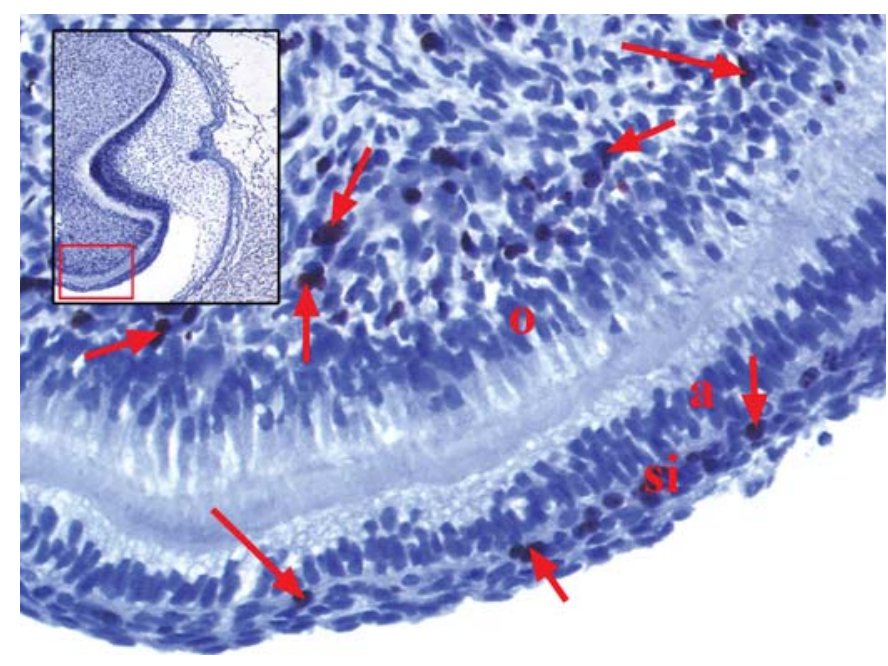

Fig. 4. Ki-67-negative matrix producing ameloblasts (a) and odontoblasts (o). Positive immunostaining is apparent in the stratum intermedium (si) and dental papilla (arrows). Mandibular primary first molar. Original magnification $200 \times$. Inset Low magnification $(25 \times)$ of the mandibular primary first molar, indicating the region of higher magnification.

formed on the surface of the dental papilla opposing the layer of preameloblasts. Odontoblasts and preameloblasts underwent terminal differentiation to secrete precursors of first dentin and then enamel (fig. 4). Under the odontoblastic layer, dental papilla fibroblasts showed positive $\mathrm{Ki}-67$ immunostaining. Cells of the stratum intermedium

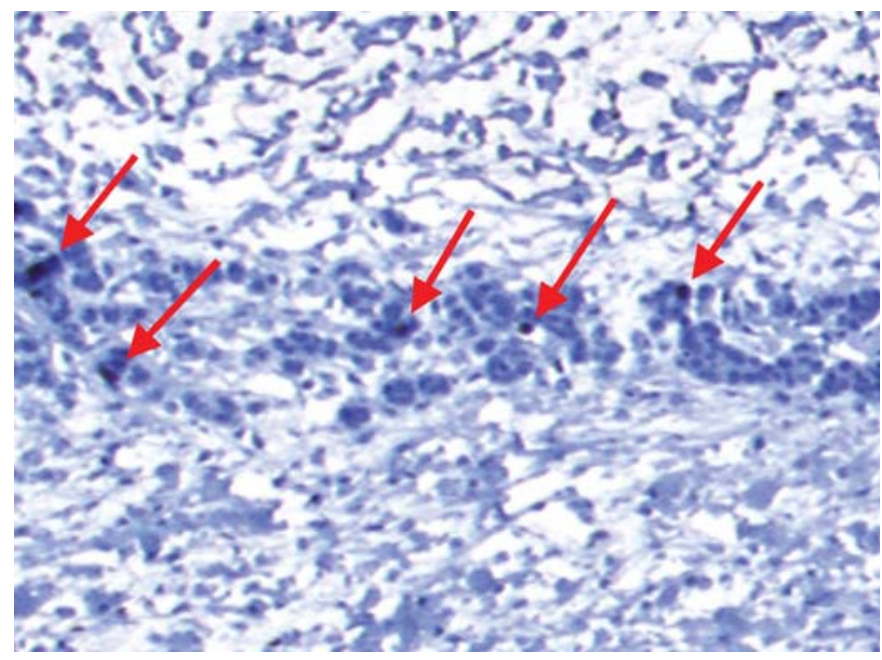

Fig. 5. Increased degeneration and decreased Ki-67 immunostaining (arrows) in the dental lamina at the early bell stage of the mandibular primary first molar. Original magnification $200 \times$.

were also positive for Ki-67. In contrast to the stratum intermedium and dental papilla, the ameloblasts and odontoblasts which were producing matrix were no longer immunoreactive (fig. 4). Degeneration of the dental lamina continued in the early bell stage. Only a few immunoreactive cells were seen in the dental lamina (fig. 5).

\section{Week 30 of Gestation}

The tooth had reached the late bell stage, and dentinogenesis and amelogenesis had begun at the tip of the cusps. A gradual increase of Ki-67 staining was observed in the inner enamel epithelium from the incisal area in the direction of the apex (fig. 6). Staining of dental-papilla cells also increased in the same direction. Ki-67 immunostaining was detected in the inner enamel epithelium and in the dental papilla cells of the cervical area of the tooth germ, while being completely absent in mature ameloblasts and odontoblasts that were producing hard dental tissues (fig. 6). The dental-lamina cells almost totally disintegrated and disrupted at this stage. The immunostaining of the cells was completely negative (fig. 7).

\section{Discussion}

Immunohistochemical demonstration of proliferation-related markers is an effective method for understanding the proliferative potential of cells. Immunohistochemical studies using proliferation-related markers 


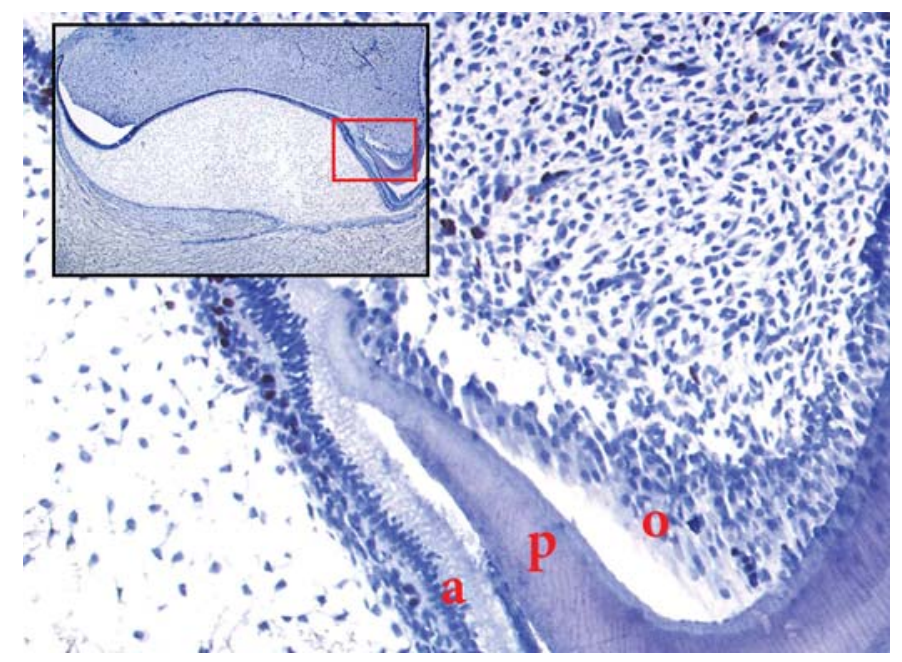

Fig. 6. An increasing gradient of Ki-67 staining in the incisal to apical direction in the inner enamel epithelium and dental papilla. Mature ameloblasts (a) and odontoblasts (o) show negative immunoreactivity. Mandibular primary first molar. Original magnification $50 \times . \mathrm{p}=$ Predentine. Inset Low magnification $(25 \times)$ of the mandibular primary first molar, indicating the region of higher magnification.

have focused on antibodies comprising Ki-67, the Ki-67 clone MIB-1 and proliferating cell nuclear antigen (PCNA) [7, 9, 16, 19-21]. These cell-cycle-dependent antibodies are quite sensitive. However, PCNA is expressed in the entire cell cycle including the $\mathrm{G}_{0}$ phase [22]. On the other hand, the Ki- 67 antigen is expressed in proliferative cells throughout the $G_{1}, S, G_{2}$ and $M$ phases, but not in the $\mathrm{G}_{0}$ phase [23]. Due to this difference, the Ki-67 antigen provides an immunohistochemically reliable index of cellular proliferation. It is well known that when extracellular conditions are unfavorable, cells stop proliferation in the $G_{1}$ phase and may enter a specialized resting state known as $G_{0}$ phase, in which they can remain for days, weeks or even years before resuming proliferation [24].

Disruption of the dental lamina results in a loss of connection between the tooth germ and the oral epithelium during odontogenesis. Using the terminal deoxynucleotidyl transferase-mediated nick end labeling (TUNEL) method, Vaahtokari et al. [5] demonstrated apoptotic cells in the dental lamina and adjacent outer enamel epithelial cells at the bell stage. Recently, Matulova et al. [8] detected the proliferation capacity of the tooth primordia in the field vole using PCNA. According to their findings, the dental lamina shows proliferative activity in the bud stage. They also reported that the proliferative capacity of

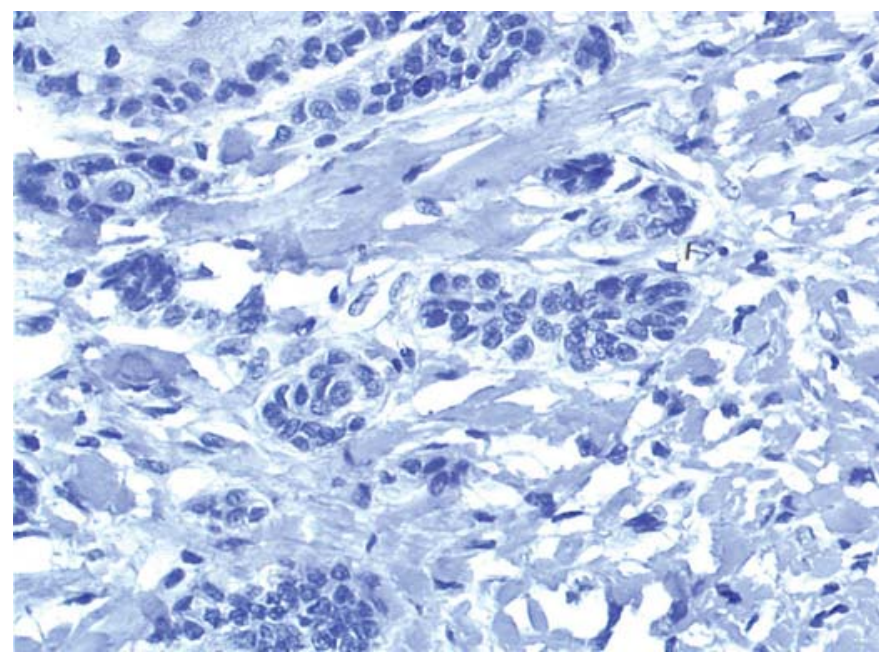

Fig. 7. Dental lamina cells showing almost total disruption in the mandibular primary first molar. Immunostaining of cells is completely negative. Original magnification $200 \times$.

the dental lamina cells decreased in the later stages of tooth development, and that they could not observe the dental lamina at the bell stage.

Our results show that the proliferative activity of human dental lamina cells decreases during tooth development. Disruption of these cells starts at the late cap stage (week 16 of gestation) and becomes almost complete at the late bell stage (week 30 of gestation). The proper disruption of the dental lamina has clinical significance, since the clusters of epithelial cells from dental lamina remnants may form cysts over the developing tooth and delay eruption. The remnants of the dental lamina are accepted as one of the main sources of odontogenic cysts and tumors. Studies evaluating the proliferation capacity of odontogenic cyst cells have shown positive Ki-67 immunostaining $[7,11]$. These results emphasize that if dental lamina cells fail to disrupt in the developmental stages and lose their proliferative activity, they may continue to proliferate and, thus, initiate formation of developmental odontogenic cysts.

The pattern of cell proliferation during tooth development has been widely studied in the rodent model $[9,15$, $16,25]$. These studies demonstrated the distribution pattern of proliferating cells during tooth development using 5-bromo-2'-deoxyuridine or PCNA, and showed similar results to our study with the exception of the gestational 
stages. In the present study, Ki-67 was detected in a wide range of mesenchymal and epithelial cells of tooth primordia during odontogenesis. In early developmental stages, all parts of the developing tooth were stained because of the rapid development and proliferation capacity of the tissues. In the late cap and early bell stages, the Ki67 content of cells decreased as a consequence of the differentiation of certain cell populations, such as ameloblasts and odontoblasts. Our observations on the proliferative activity of human ameloblasts and odontoblasts are in agreement with previous work suggesting that ameloblasts and odontoblasts stop proliferating after they have begun to secrete matrix $[8,15,16,25]$. The maturation and matrix secretion start from the incisal region in a cervical direction $[5,8,15,16]$. Therefore, an increasing gradient of Ki-67 staining in a direction from incisal to apical was observed in the inner enamel epithelium. Staining of dental papilla cells also increased in the same direction. No staining was detected in the mature ameloblasts and odontoblasts residing at the cusped ridge.

\section{Conclusion}

The Ki-67 immunoreactivity of the dental lamina decreased during intrauterine tooth development. Positive immunostaining was observed at specific sites in the enamel organ and dental papilla during the cap and bell stages.

\section{References}

1 Cobourne MT: The genetic control of early odontogenesis. Br J Orthod 1999;26:21-28.

2 Charlson BM: Development of the head, neck, and lymphoid system; in Charlson BM (ed): Pattern's Foundations of Embryology. New York, McGraw-Hill Inc., 1996, pp 528537.

-3 Baratella L, Arana-Chavez VE, Katchbrian E: Apoptosis in the early involuting stellate reticulum of rat molar tooth germs. Anat Embryol 1999;200:49-54.

-4 Hovorakova M, Lesot H, Peterka M, Peterkova R: The developmental relationship between the deciduous dentition and the oral vestibule in human embryos. Anat Embryol 2005;209:303-313.

5 Vaahtokari A, Aberg T, Thesleff I: Apoptosis in the developing tooth: association with an embryonic signaling center and suppression by EGF and FGF-4. Development 1996;122: 121-129.

-6 Beckor KB, Hansen BF, Nolting D, Kjær I: Spatiotemporal expression of NGFR during pre-natal human tooth development. Orthod Craniofacial Res 2002;5:85-89.

> Saraçoğlu U, Kurt B, Günhan Ö, Güven O: MIB-1 expression in odontogenic epithelial rests, epithelium of healthy oral mucosa and epithelium of selected odontogenic cysts. An immunohistochemical study. Int J Oral Maxillofac Surg 2005;34:432-435.

$\checkmark 8$ Philipsen HP, Reichart PA, Ogawa I, Suei Y, Takata T: The inflammatory paradental cyst: a critical review of 342 cases from a literature survey, including 17 new cases from the author's files. J Oral Pathol Med 2004;33:147155.

>9 Matulová P, Witter K, Mísek I: Proliferating cell nuclear antigen (PCNA) expression in tooth primordia in the field vole (Microtus agrestis, Rodentia). Connective Tissue Res 2002;43:138-142.
10 Wrobel KH, Bickel D, Kujat R: Immunohis tochemical study of seminiferous epithelium in adult bovine testis using monoclonal antibodies against Ki-67 protein and proliferating cell nuclear antigen (PCNA). Cell Tissue Res 1996;283:191-201.

- 11 Edamatsu M, Kumamoto H, Ooya K, Echigo $\mathrm{S}$ : Apoptosis-related factors in the epithelia components of dental follicles and dentigerous cysts associated with impacted third molars of the mandible. Oral Surg Oral Med Oral Pathol Oral Radiol Endod 2005;99:1723.

12 Chrysomali E, Nikitakis NG, Tosios K, Sauk JJ, Papanicolau SI: Immunohistochemical evaluation of cell proliferation antigen Ki-67 and apoptosis-related proteins $\mathrm{Bcl}-2$ and caspase-3 in oral granular cell tumor. Oral Surg Oral Med Oral Pathol Oral Radiol Endod 2003;96:566-572.

13 Lindboe CF, Torp SF: Comparison of Ki-67 equivalent antibodies. J Clin Pathol 2002;55: 467-471.

14 Matalova E, Antonarakis GS, Sharpe PT, Tucker AS: Cell lineage of primary and secondary enamel knots. Dev Dyn 2005;233: 754-759.

15 Nakasone N, Yoshie H, Ohshima H: An immunohistochemical study of the expression of heat-shock protein-25 and cell proliferation in dental pulp and enamel organ during odontogenesis in rat molars. Arch Oral Biol 2006;51:378-386.

16 Nakasone N, Yoshie H, Ohshima H: The relationship between the termination of cell proliferation and expression of heat-shock protein-25 in the rat developing tooth germ. Eur J Oral Sci 2006;114:302-309.
-17 Kondo S, Tamura Y, Bawden JW, Tanase S: The immunohistochemical localization of $\mathrm{Bax}$ and $\mathrm{Bcl}-2$ and their relation to apoptosis during amelogenesis in developing rat molars. Arch Oral Biol 2001;46:557-568.

18 Iacop S, Veis A: Identification of temporal and spatial expression patterns of amelogenin isoforms during mouse molar development. Eur Oral Sci 2006;114(suppl 1):194200.

19 Kim KD, Ahn SG, Kim J, Yoon JH: Comparative Ki-67 expression and apoptosis in the odontogenic keratocyst associated with or without an impacted tooth in addition to unilocular and multilocular varieties. Yonsei Med J 2003;44:841-846.

$\checkmark 20$ de Paula AMB, Carvalhais JN, Domingues JN, Barreto DC, Mesquita RA: Cell proliferation markers in the odontogenic keratocyst: effect of inflammation. J Oral Pathol Med 2000;29:477-482.

21 Slootweg PJ: P53 protein and Ki-67 reactivity in epithelial odontogenic lesions. An immunohistochemical study. J Oral Pathol Med 1995;24:393-397.

$>22$ Otha Y, Ichimura K: Proliferation markers, proliferating cell nuclear antigen, Ki67, 5-bromo-2'-deoxyuridine, and cyclin D1 in mouse olfactory epithelium. Ann Otol Rhinol Laryngol 2000;109:1046-1048.

23 Qin LX, Tang ZY: The prognostic molecular markers in hepatocellular carcinoma. World J Gastroenterol 2002;8:385-392.

24 Alberts B, Johnson A, Lewis J, Raff M, Roberts K, Walter P: Molecular Biology of the Cell. New York, Taylor \& Francis Group, ed 4, 2002, pp 984-990.

-25 Shigemura N, Kiyoshima T, Koyabashi I, Matsuko K, Yamaza H, Akamine A, Sakai H: The distribution of BrdU- and TUNEL-positive cells during odontogenesis in mouse lower first molars. Histochem J 1999;31:367-377. 